\title{
Suggestions for Treatment of Schizophrenia
}

\author{
Anna Cornelia Beyer* \\ Centre for Security Studies, School of Law and Politics, University of Hull, UK
}

\section{Opinion}

I am a scientist at the University of Hull in the Social Sciences, and a patient myself with schizophrenia since 2002 [1]. In my free time, I have researched schizophrenia and alternative treatments, and I would like to make some suggestions on how to improve the treatment of schizophrenic patients based on my own experience. I am not trained in psychiatry or biology, but I am a scientist, and I had the advantage that I could test all treatments on myself and experience any effects first hand.

First, let me say some words about schizophrenia per se. It is believed to usually start in early adulthood (around 20 for men, 30 for women) [2] and is often connected to trauma of whatever sort $[3,4]$. This can be overwork, unemployment, any shock, such as death of a loved one or a failure at education or whatnot.

The illness itself presents as disturbed perceptions that usually take the form of spiritual, quasi-spiritual or paranormal perceptions. For example, most people hear voices in their head that no one else can hear. This resembles what telepathy or spirit communication could feel like, if they existed (based on own experience). Other symptoms, such as seeing entities that no one else can see, tactical hallucination (feelings of being touched) etc. are also common. Very often these perceptions turn so negative and haunting over time that the patient becomes paranoid and dysfunctional. Disability and unemployment are very common in schizophrenic patients, suicide is 10 -fold increased, aggression is somewhat higher, life expectancy is 10 to 15 years reduced [5-14].

Traditional medicine relies mostly on neuroleptic medication for treatment. These are basically major tranquilizers who work on the dopamine circle in the brain, where the fault is believed to lie $[15,16]$. They help reasonably well and are believed the cause why many patients can live now in their communities, where before they had to be kept in hospitals. However, current treatments are not good enough to restore full functionality in many patients; disability, unemployment and suicide are still very, very high.

From my own experience of schizophrenia, I would like to make some suggestions on how the treatment of schizophrenia can be improved to help remedy these problems.

I have lived and worked since 2007 at the University of Hull and have been in fulltime employment all this time even though I had a diagnosis of schizophrenia. What I feel has helped me most was to take a very low level of medication only - the research indicates that lower level medication helps people recover better [17-20] and instead supplement this with an intensive treatment of lifestyle and dietary adaptations.

For example, I turned pescatarian, I eat extremely healthfully (lots of fruit and veg, I do juicing every day, one lady cured herself of schizophrenia with a raw vegan diet [21] and pescatarian diets - no meat, but fish - have been found to be the diets of the longest living civilisations) [22-24], I avoid gluten and milk if possible (gluten and milk free diets have been found beneficial for some patients) [2529], I try to avoid smoking and reduce coffee and alcohol and do exercise. Coffee seems especially important. It has been found to produce the symptoms of voice hearing even in healthy individuals when taken in excess and many patients with schizophrenia abuse it. According to Fuller Torrey, the schizophrenia epidemic started around the time when coffee and nicotine became more widely used in the developed world in 1750 [30-32]. Reduction in coffee is very important. For smoking abstinence, I use nicotine gum and e-cigarettes. Alcohol reduction is also important. Stimulants and soft drugs can bring about hallucinations. This might not necessarily be only cannabis, which has been linked to schizophrenia in the past, but can also be any of the other stimulants or soft drugs. Exercise is important for anyone, and a healthy exercise routine helps avoid anxiety and combat stress. A very important practice seems to be the supplementation with vitamins.

Abram Hoffer has found that he could cure schizophrenia (as he claimed) with high doses of Niacin (vitamin B3), Omega 3 and Vitamin C [33-35]. I have followed this approach for about 10 years and found it very beneficial. I believe I could not have continued to work fulltime without this practice. I would however stress that I think one needs to also supplement with a good B complex formula. While I functioned well enough on Hoffers treatment for 10 years to work fulltime (that is I took the recommended vitamins and 2-4 mg Risperidone in addition to my healthy lifestyle) I improved when I added a good B complex formula. I used Declinol for that purpose initially, it immediately got me rid of the remaining symptoms of voice hearing for some time. It is possible that one

Correspondence to: Anna Cornelia Beyer, Senior Lecturer, Deputy Director of the Centre for Security Studies, School of Law and Politics, University of Hull, Hull HU67RX, UK, Tel: 01482 466342; Tel: 07554193888; E-mail: c.beyer@hull.ac.uk

Received: February 05, 2019, Accepted: February 27, 2019, Published: March 01, 2019

Citation: Beyer AC (2019) Suggestions for Treatment of Schizophrenia. Biomedical Journals. 8:251. doi: 10.35248/2168-975X.19.8.251

Copyright: (C) 2019 Beyer AC. This is an open-access article distributed under the terms of the Creative Commons Attribution License, which permits unrestricted use, distribution, and reproduction in any medium, provided the original author and source are credited. 
can also use a cheaper B complex formula with 5HTP added (a natural antidepressant).

I speculate that intensive use of coffee, nicotine and stress over time deplete B vitamins and this can cause schizophrenia.

So, in essence, my treatment programme is a combination of lifestyle and dietary interventions in addition to low level medication:

- Low level medication

- Pescatarian diet (fish, fruit veg; bread and dairy should be taken with caution, as some people with schizophrenia suffer from gluten and milk intolerance)

- Lots of fresh fruit and veg, juicing is a very good option to get sufficient nutrients, fresh vegetable juices are best.

- Also, protein supply needs to be taken care of. This can be from fish, soymilk, beans, etc.

- Exercise: At least half an hour of exercise a day is recommended. Most people with schizophrenia prefer gentle exercises, such as walking.

Supplementation with vitamins: Hoffers recipe works well (1-more g Niacin a day, Niacin is similar to nicotine, and could maybe even help with smoking reduction [36], $3 \mathrm{~g}$ Omega 3, several times a day if needed, works like brainfood, at least $1 \mathrm{~g}$ Vitamin C, which also prevents cancer and the common cold) plus a good vitamin B formula. Reduction or limitation or avoidance of stimulants and soft and hard drugs are an option. For smoking, nicotine replacement therapies are a good option. Coffee should also only be taken in sensible measures, maybe up to 5 cups a day, not more. Many schizophrenics abuse coffee and nicotine [37-39], if there are not additional other substance abuse problems, and all of them can bring about the symptoms of schizophrenia. Coffee can bring about the symptoms of voice hearing $[40,41]$.

Spirituality and meditation also seem beneficial. I am following spirituality through daily prayer and reading about spirituality, I also meditate regularly. The loving kindness meditation has been very helpful for me personally [42]. That is to meditate on the following: Let me be happy and healthy and safe, let my family be happy and healthy and safe, let everyone in the world be happy and healthy and safe. Other meditations might be useful as well, according to need and taste, but this one is good for reducing aggression and support better social functioning.

Talking and alternative therapies might also be a good supplement for overcoming trauma or other additional problems.

From my own personal stand-point, I believe this combination is the best method to help people with schizophrenia lead a fulfilling and healthy life, allow for employment and relationship success, and avoid early death or suicide. It is the combination of all the various things I read about and tried myself, and I did honestly try every alternative therapy that was available to me. Some have been tested already, such as the loving kindness meditation and coffee reduction, but I believe in their combination they work far superior than relying on traditional medication alone.

Now, for the second part of this presentation I will speculate a little bit about what could cause schizophrenia. Please forgive me if this sounds amateurish, as I said I'm not trained in psychiatry, medicine or biology, I'm just a social sciences scientist who is also a patient.
My first episode in 2002 I represented like a spiritual phenomenon. It felt like channelling, and out of body experience, and telepathy. It did intensively feel like a spiritual experience. I believe it was brought about by isolation, hard work and self-starvation at the time, in addition to trauma that was presented due to $9 / 11$ and all the panic that followed, including two deaths in my personal relationships.

My later illness represented as voice hearing mainly and I believe has been caused by abnormal coffee consumption. Coffee is known to be consumed under stress, as well as nicotine, and both can cause hallucinations in themselves. Coffee has been shown to be able to cause voice hearing, and tobacco has been used by shamans to induce visionary states. Both are used under stress by many people, and people with schizophrenia are known to often abuse them. $90 \%$ of people with schizophrenia smoke, far more than the general population, and from hospital settings it is known that many patients abuse coffee.

Coffee and nicotine do deplete B vitamins, hence reduction in both and supplementation with B complex can probably help $[43,44]$.

Other dietary abuses, such as alcohol and cannabis or drugs of course can also cause hallucinations and should be worked on independently in schizophrenia patients.

From the literature and evidence, I found on the internet, I want to state I found only a handful of accounts of people who claimed to have cured themselves.

- One used intensive prayer.

- One used a raw vegan diet.

- One used vitamin.

- One used dialysis.

This indicates that brain poisoning might be the cause of schizophrenia, healthy, clean nutrition with vitamin support and cessation or reduction of offending foods or stimulants or drugs might help, and spirituality might also be of benefit.

I conducted a small-scale survey with patients on a schizophrenia Facebook forum. In this survey, I found 3 individuals who claimed that they had recovered for more than 10 years. 2 of them did not use medication for their recovery, one used medication. All of them used spirituality. Of all recovered, one was a vegan and one used Omega 3 and one used fasting [45]. Overall, this combination seems to be the winning combination from all I learned in intensive research and self-experiment over 10 years:

- Clean nutrition, ideally avoiding meat, including lots of fresh fruit and veg, can include fish or be vegetarian or even vegan. Gluten and dairy intolerance should be checked for.

- Vitamin supplementation (B3, Omega 3, Vitamin C, B complex)

- Healthy lifestyle (Sport, Leisure, etc.)

- Spirituality (Prayer, Meditation)

- Low level traditional medication if needed, maybe more in emergencies

- Avoidance or reduction of stimulants and drugs

I found a recent study that has tested an intervention with multiple 
lifestyle enhancing treatments. And this study found that this could reduce medication need in patients.

In conclusion, I would like to call for the need to look into how treatments of people with schizophrenia can be improved, and these are my recommendations, based on 10 years intensive research and self-experimentation. I have written a book about it, you find the flyers for this book here. A reliance on traditional medication alone is not sufficient and does not cure patients. Also, side effects are often very disturbing. We need better approaches, and diet and nutrition etc. are sensible, common sense, cheap interventions that not only might help reduce mental illness but will also improve physical health in patients.

Finally, I would like to mention that it is strange that no one has conducted a study on recovered patients yet. It is said that up to $50 \%$ of patients recover completely. One should question these patients on how they achieved their recovery, a common-sense approach that so far has not been pursued.

\section{References}

1. Royal B. A hopeful tale from the wonderland of psychosis. NPJ Schiz. 2015.

2. Beyer AC. Health and safety for spirit seers, telepaths and visionaries. Self-help for Schizophrenia. Cambridge: Cambridge Scholars Publishing. 2019.

3. Hammersley P, Read J, Woodall S, Dillon J. Childhood trauma and psychosis: The genie is out of the bottle. Journal of psychological trauma. 2008;6:7-20.

4. Karon BP. Trauma and schizophrenia. Journal of Psychological Trauma. 2008;6:127-144.

5. Wu EQ, Birnbaum HG, Shi L, Ball DE, Kessler RC. The economic burden of schizophrenia in the United States in 2002. J Clin Psychiatry. 2005;66:1122-1129.

6. Walsh E, Buchanan A, Fahy T. Violence and schizophrenia: Examining the evidence. Br J Psychiatry. 2002;180:490-495.

7. Unknown undated Life expectancy in schizophrenia and years of potential life lost.

8. Galletly CA. Premature death in schizophrenia: Bridging the gap. Lancet Psychiatry. 2017;4:263-265.

9. Goff DC, Cather C, Evins AE, Henderson DC, Freudenreich O. Medical morbidity and mortality in schizophrenia: guidelines for psychiatrists. J Clin Psychiatry. 2005;66:183-194.

10. Laursen TM, Nordentoft M, Mortensen PB. Excess early mortality in schizophrenia. Annu Rev Clin Psychol. 2014;10:425-448.

11. Lawrence D, Kisely S, Pais J. The epidemiology of excess mortality in people with mental illness. Can J Psychiatry. 2010;55:752-760.

12. Hor K, Taylor M. Suicide and schizophrenia: a systematic review of rates and risk factors. J Psychopharmacol. 2010;24:81-90.

13. Palmer BA, Pankratz VS, Bostwick JM. The lifetime risk of suicide in schizophrenia: A re-examination. Arch Gen Psychiatry. 2005;62:247-253.

14. Roy A. Suicide in chronic schizophrenia. Brit J Psychiat. 1982;141:171-177.

15. Howes OD, Kapur S. The dopamine hypothesis of schizophrenia: Version III-The Final Common Pathway. Schiz Bull. 2009;35:549-562.

16. Jentsch JD, Roth RH. The neuropsychopharmacology of phencyclidine: from NMDA receptor hypofunction to the dopamine hypothesis of schizophrenia. Neuropsychopharmacology. 1999; 20:201-225.
17. Harrow M, Jobe TH. Factors involved in outcome and recovery in schizophrenia patients not on antipsychotic medications: A 15-year multi follow-up study. J nerv ment dis. 2007;195:406-414.

18. Williams P. Rethinking madness: Towards a paradigm shift in our understanding and treatment of psychosis. Sky's Edge Publishing, San Raphael. 2014.

19. Wyatt RJ. Neuroleptics and the natural course of schizophrenia. Schizophr Bull. 1991;17:325-351.

20. Watkins J. Healing schizophrenia using medication wisely. Michelle Anderson, Melbourne, Australia. 2006.

21. http://www.raw-food-health.net/Victoria-Everett.html

22. Ginter E . Vegetarian diets, chronic diseases and longevity. Bratisl Lek Listy. 2008;109:463-6.

23. McEvoy C, Temple N, Woodside J. Vegetarian diets, low-meat diets and health: A review. Public Health Nutr. 2012;15:2287-2294

24. Marsh K, Zeuschner C, Saunders A. Health implications of a vegetarian diet. Am J Life. 2011;6:250-267.

25. Orlich MJ, Singh PN, J Sabatep. Vegetarian dietary patterns and mortality in Adventist health study 2. JAMA Intern Med. 2013;173:1230-1238.

26. Kraft BD, Westman EC. Schizophrenia, gluten, and low-carbohydrate, ketogenic diets: A case report and review of the literature. Nutr Met. 2009;6:10.

27. Samaroo D, Dickerson F, Kasarda DD, Green PH. Novel immune response to gluten in individuals with schizophrenia. Schizophr Res. 2010;118:248-55.

28. Singh MM. Wheat gluten as a pathogenic factor in schizophrenia. Science. 1976;191:401-402.

29. Kalaydjian AE, Eaton W, Cascella N, Fasano A. The gluten connection: The association between schizophrenia and celiac disease. Acta Psychiatr Scand. 2006;1132:82-90.

30. Torrey EF, Miller J. The invisible plague: The rise of mental illness from 1750 to the present. Rutgers University Press, USA. 2008; 95:818-818

31. Smith RF. A history of coffee. In: Smith, R.F.: Coffee. Boston: Springer. 1985;1-12.

32. Norton M. Sacred gifts, profane pleasures: a history of tobacco and chocolate in the Atlantic world. Ithaca: Cornell University Press, USA. 2008; 96:514-514.

33. Hoffer A. Orthomolecular treatment for schizophrenia. New York: Mc Graw Hill, NY, USA. 1995;373-321.

34. Hoffer A, Saul A. Orthomolecular medicine for everyone: Megavitamin therapeutics for families and physicians. Laguna Beach: Basic Health Publications. 2008.

35. Hoffer A. How to Live with Schizophrenia. Kensington, New York, USA. 1998.

36. Clarkes R. Niacin for nicotine? Lancet. 1980;315:8174-936.

37. Mikkelsen EJ.Caffeine and schizophrenia. J Clin Psychiat. 1978;39:732-736.

38. Lucas PB, Pickar D, Kelsoe J. Effects of the Acute Administration of Caffeine in Patients with Schizophrenia. Biol Psychiat. 1990;28:35-40.

39. Koczapski A, Peredes J, Kogan C. Effects of caffeine on the behaviour of schizophrenic inpatients. Schizophrenia Bull. 1989;15:339-344.

40. Grohol J undated Hearing voices or seeing things? Cut back on the coffee. 
41. Crowe SF, Barot J, Caldow S. The effect of caffeine and stress on auditory hallucinations in a non-clinical sample. Pers Indiv Differ. 2011;50:626-630.

42. Ulvik A, Vollset SE, Hoff G. Coffee consumption and circulating B-vitamins in healthy middle-aged men and women. Clin chem. 2008;54:1489-1496.

43. Ulvik A, Ebbing M, Hustad S. Long-and short-term effects of tobacco smoking on circulating concentrations of B vitamins. Clin chem. 2010;56:755-763.

44. Beyer AC. Health and safety for spirit seers, telepaths and visionaries. Self-help for Schizophrenia. Cambridge: Cambridge Scholars Publishing, UK. 2019.

45. Deenik J. Less medication use in patients with severe mental illness receiving a multidisciplinary lifestyle enhancing treatment. Front Psy. 2018;18:707. 